\title{
The Factors and Features of Museum Fatigue in Science Centres felt by Korean students
}

\begin{abstract}
One of the objectives of science education in science centres has been the enhancement of interest in science. However, museum fatigue has a negative impact on interest. Museum fatigue has been described as physical tiredness or a decrease in visitors' interest in a museum. The learning experience of students in science centres is also influenced by museum fatigue. The purpose of this study is to identify the phenomena of museum fatigue in science centres and to identity how it is manifested. First, we identified the factors causing museum fatigue in science centres using the data from an open-ended questionnaire which was given to 597 primary, middle and high school students in South Korea. From the responses to the questionnaire, 50 factors causing museum fatigue in science centres were identified. A second Likert-type questionnaire with the 50 factors of museum fatigue in science centres was administered to 610 primary, middle and high school students in South Korea. Using reliability and factor analyses, we developed a framework of the factors causing museum fatigue in science centres, which consists of three contexts, 12 categories, and 50 factors. Secondly, through statistical analyses including T-test and ANOVA analysis, the features of students' museum fatigue in science centres were analysed and compared regarding student gender, school level, interest in science, grade of school science, the number of visits, and type of visit. The results, which were found to be statistically significant, are reported and discussed. The findings of this study are intended to add to our understanding of science learning in science centres which may aid in developing more effective teaching approaches.
\end{abstract}

Keywords: museum fatigue in science centres, interest in science, contextual model of learning, informal learning 


\section{Introduction}

This study covers research on informal science education in the context of science centres. Most science centres have been established for the purpose of public science education (Friedman, 2010). One of the objectives of science education in science centres has been the enhancement of interest in science (Rennie \& Williams, 2002). However, how much do the visitors get interested in science to accomplish their educational aim? To answer the question, we hypothesised that one of the most significant factors which could lessen the interest in science centres is museum fatigue.

Studies on 'museum fatigue,' a phenomenon where people lose their interest in museums, have been undertaken for nearly a century, starting from Gilman (1916) to, more recently, Bitgood (2009). According to Davey (2005, p. 20), "museum fatigue is a collection of phenomena that present predictable decrease in visitor interest and selectivity." He had extracted the concept from the earlier studies and proposed the comprehensive definition. Nevertheless, to define museum fatigue is not easy, since the term, its meaning and its factors have been used in various contexts (Bitgood, 2009).

Previous studies have shown that there is growing conception about the definition and factors of museum fatigue. Gilman (1916) is the one who first coined the term 'museum fatigue.' At that time, it was regarded as a physical phenomenon. 'Museum fatigue' was defined as a physical tiredness that comes from seeing exhibitions. Although Gilman's work is significant in that it was the first study done on the topic, the study has its limits, as it only took physical factors into consideration (Robinson, 1928). To overcome this shortage, Melton (1935) suggested that the number of exhibits should be taken into account as another factor of museum fatigue. Since then, the field of museum fatigue studies has expanded to cover the environmental factors related to the museum itself. A study done by Falk et al. (1985) suggested that the interest of visitors reaches its peak during the early stage of viewing, remains at its peak for 30 minutes, and decreases over time after the 30 minutes. Also, the environmental factors of the museum and the relation between environmental factors and museum fatigue have been discussed. This analysis shed light on the relationship between the order of exhibits and museum fatigue. Marcellini and Jenssen (1998) found that the time visitors spent at specific exhibits is longer at the beginning of their tour than at the end. Cota-Mckinley (1999) defined museum fatigue regarding workload probe which was done through a survey using criteria (i.e., mental effort, physical effort, time pressure, work performance and frustration). He also found that the number of exhibition rooms in the museum affected the degree of physical effort expended by visitors. Davey (2005) developed a new definition of museum fatigue, which included the results from many of the previous studies. According to his definition (Davey, 2005, p. 20), museum fatigue is:

"a collection of phenomena that represent predictable decreases in visitor interest and selectivity either during entire visits, within smaller areas (such as exhibit galleries), or across a few successive exhibits. These decreases are likely to be attributed to a combination of visitor factors (such as cognitive processing, physical fatigue, and individual characteristics), factors in the environment 
(such as exhibit architecture and the museum setting), and interaction between them."

Bitgood (2009) argues that the duration of a visit is not proportional to the time people spend in front of individual exhibits. He also argues that 'the concept of interest and attentive concentration is not equal,' this being a different conclusion compared to previous studies. Furthermore, he suggested seven phenomena associated with museum fatigue: fatigue, satiation, stress, information overload, competition, limited cognitive capacity, and decision making.

Within the research community, researchers have focused on the phenomenon where visitors lose their concentration or interest in museums. Interest has a significant effect on the affective domain of students regarding learning (Ainley, Hidi, \& Berndorff, 2002; Pompes, Walker, \& Spark, 2008; Renninger \& Hidi, 2011). In this sense, museum fatigue is believed to have a significant effect on student learning in museums, as fatigue in museum learning could arise from the loss of interest in learning (Davey, 2005; Bitgood, 2009) and education in museums occurs in different kinds of educational environments that primarily affect museum fatigue (Robinson, 1928; Davey, 2005; Bitgood, 2009).

Although museum fatigue related to interest also has to do with attitude to science in science centres, many studies only concerning the kinds and features of interest which have an effect on learning have been undertaken (Schiefele, 1998; Csikszentmihalyi \& Hermanson, 1999; Ainley, Hidi, \& Berndorff, 2002; Pompes, Walker, \& Spark, 2008; Renninger \& Hidi, 2011; Lamb et al., 2011). However, research about museum fatigue in science centres could hardly be found. Although Bitgood (2009) widened the research horizon by suggesting seven phenomena associated with museum fatigue, it seems that there are still many aspects yet to be investigated.

Therefore, it is meaningful to conduct a systematic and inclusive study regarding the factors and characteristics of museum fatigue in science centres in terms of an increase in interest in science. In the paper, we focused on two areas: first, the creation of a conceptual framework for museum fatigue in science centres that can be used by researchers, developers, and educators to understand visitor learning, to evaluate exhibits, and to design learning experiences for students who visit science centres; second, to enunciate the characteristics of museum fatigue in science centres to find the way to enhance interest in science in science centres. Through these two surveys, the factors and features of museum fatigue in science centres were investigated. The results of this study show the characteristics of learning regarding museum fatigue in science centres and ways to enhance the interest in science centres. The implication could support museum designers and guide science educators in planning for school or individual visitors.

Most students who took part in this research had visited science centres, namely Gwacheon National Science Museum, Seoul National Science Museum and LG Science Hall. These science centres are located in the Seoul and Gyeonggi provinces in Korea, near where the students who take part in the research live. Gwacheon National Science Museum was built in 2008 and is a typical science centre. About two million visitors visit this museum every year. The museum consists of various kinds of exhibit halls, which have various topics such as basic science, advanced technology, traditional science, 
astronomy, natural history, and ecology. It displays about seven hundred exhibits. Seoul National Science Museum was opened in 1979 and is affiliated to the Gwacheon National Science Museum. This museum has exhibition space of eleven thousand and two hundred sixty-two square meters and shows exhibits about the history of science and technology, natural history, and industry technology. The LG science hall was opened in 1987 to enhance the importance of science education for students. This facility has been designed to encourage students in scientific activities, where they can learn about how science works to make our lives better and how we can use science to preserve our environment. This hall has more than two hundred thousand student visitors every year. The LG Science Hall is the only private museum and access to exhibits is only available via guided tour. The remaining museums are public and allow open access. These museums are third-generation science museums (Friedman, 2010) which emphasise a concrete experiences, hands-on activities, and audience participation. Since public education became the core purpose for science museums, the word "museum" was substituted by centre (Friedman, 2010). Therefore, we refer to Gwacheon National Science Museum, Seoul National Science Museum and LG Science Hall as "science centres" instead of "science museums".

\section{Methodology}

In this study, a framework of factors causing museum fatigue in science centres was developed, and the characteristics of it were analysed. Two surveys were conducted with primary [Year 5 6], middle [Year 7 9] and high [Year 10 12] school students in Korea to develop the framework and to investigate the features of students' museum fatigue in science centres. The procedure of this research can be divided into two parts: development and analysis.

\section{1 (Development) Developing a framework of factors causing museum fatigue in science centres}

According to the Contextual Model of Learning (CML) (Falk \& Dierking, 2000, 2002), learning is contextualised, and 'meaning' arises from the interaction between personal actions and its means (i.e. tools, speech, action structure, indications, and symbol systems) regarding social context. CML also emphasises the context in science learning by suggesting that learning contexts in science centres can be divided into three types (i.e., personal context, socio-cultural context, and physical context), each with sub-contextual factors (Falk \& Dierking, 2000; Hong \& Song, 2013). The theoretical framework provided by the contextual model of learning enabled us to understand learning in museums especially in terms of three contexts which are the personal, sociocultural, and physical context (Falk \& Storksdieck, 2005).

In the development part of this research, the first survey with an open-ended item was conducted on 597 students and the second survey with Likert-type items (See Appendix 1) was carried out on 603 students (398 male and 205 female students) to investigate various factors causing students' experience of museum fatigue in science centres. From the first study, 50 factors were identified by the grouping of 
students' responses. The idea of three contexts of CML concept (Falk \& Dierking, 2000) was borrowed, and the CML helped to design survey in term of fatigue which could be caused by individual, environment, and interaction with other people. The data from the second survey was analysed through reliability analysis and factor analyses. The resulting framework of factors causing museum fatigue in science centres consists of 3 contexts, 12 categories and 50 factors.

\section{2 (Analysis) Analysis of characteristics of museum fatigue in science centres}

In this part, the data from the second survey were analysed regarding the framework of factors causing museum fatigue in science centres with the student background variables (i.e. gender, school level, interest in science, school rankings in science, the number of visit to science centres, and type of visit to science centres). To find out the features of museum fatigue in science centres, we searched for keywords and found that factors, which are seeing time, the number of exhibits, interest, cognitive processing, and individual characteristics, all played a role in the research of museum fatigue. On the basis of these keywords, we adopted the variables of gender, school level, interest in science, grade in science, the number of visits (students were asked to report the number of their visits to science centres during the last three years), and type of visits (students were asked to choose among alone, with friends, with family, as school visit, and others in relation to their visits to science centres during the last three years). The features of museum fatigue in science centres and the group differences among students' museum fatigue in science centres were analysed using t-test and ANOVA analyses. The results, which were found to be significant, are reported here.

\section{Development of the framework of factors causing museum fatigue in science centres}

The first survey with an open-ended question - "Think about your visit to a science centre. If you have felt fatigue, what do you say were the contributing factors? - was carried out with a total of 597 male and female students (187 from primary schools [Year 5 6], 212 from middle schools [Year 7 9] and 198 from high schools [Year 10 12]) in Gyeonggi Province, Korea. From the responses which had been recalled by the students, 50 factors were identified by the grouping of students' responses (See the list in Appendix 2).

The second survey was conducted with a total of 603 students (207 from primary schools [Year 5 6], 199 from middle schools [Year 8 9] and 197 from high schools [Year 10 12]) in Gyeonggi Province, Korea. A Likert scale (1 point for 'strongly disagree' to 5 points for 'strongly agree') was used to measure how much fatigue students feel when they are exposed to each factor.

Reliability was determined by internal consistency. The value of Cronbach's $\alpha$ was fair for each context and the total, as shown in Table 1. 


\section{Table 1. Reliability analysis}

Factor analysis was carried out on the 50 factors with two steps. First, an overall analysis was done to get categories, each of which represents a group of factors that possess a similar nature. In this analysis, the oblique rotation method, which allowed correlation of variables affecting museum fatigue in science centres, was applied. Moreover, we borrowed the idea of CML (Falk \& Dierking, 2000) to classify the identified 50 factors of museum fatigue in science centres systematically. Falk \& Dierking (2000) classified the learning context in science centres into three contexts: Personal context, Physical context and Socio-cultural context. This study applied those three contexts to frame factors causing museum fatigue in science centres; the CML was practical to understand learning in museum and to appreciate that the fatigue could be caused by individual visitor, museum environment, and interactions with other people. In other words, the 50 factors from the first survey were classified into the three contexts. Second, we named the categories following the idea of the CML (Falk \& Dierking, 2000; Hong \& Song, 2013). As all the p-values of Barlett's test of sphericity was .000, and KMO (Kaiser-Mayer-Olkin) values $(.893, .815, .905, .771)$ was higher than .6 , our sample seemed to be adequate for factor analysis (Child, 1990).

\section{Fig 1. The structure of museum fatigue in science centres}

Personal context was composed of five categories: prior knowledge (i.e., background knowledge, personal experience of the content), Motivation and expectation (i.e. motives of visiting science centres, feelings toward science), Interests and beliefs (i.e. interest, concentration), Control (i.e. visitors' control over own learning) and Choice (i.e. visitors' choice over what and when to learn). The Physical context was composed of five categories: Orientation to the exhibits (i.e. explanation about exhibits), Exhibition form, Exhibition amount, Exhibition hall environment, and Convenient facility (i.e. lavatory, souvenir shop). The Socio-cultural context was composed of two categories: Interaction with visitors (i.e. the interaction between visitors) and Interaction with docents (i.e. the interaction between students and docents).

As a result of factor analysis (Table 2), the 50 factors were sorted into 12 categories (See Figure 1). As for the Personal context, factors 1 4 were classified into the Prior knowledge category, 5 7 into the Motivation category, 8 12 into the Interests and beliefs category, 13 16 into the Control category and 17 19 into the Choice category. As for the Physical context, factors 20 24 were classified into the Orientation to the exhibits category, 25 26 into the Exhibition form category, 27 28 into the Exhibition amount category, 29 35 into the Exhibition hall environment category and 36 42 into the Convenient facility category. Lastly, for the Socio-cultural context, factors $43 \sim 47$ were classified into the Interaction with visitors category and 48 50 into the Interaction with docents. The full list of the framework of 
factors causing museum fatigue in science centres is given in Appendix 2.

Table 2. Factors of museum fatigue in science centres in each context by factor analysis (Oblique rotation with Kaiser Normalization)

\section{Analysis of the characteristics of museum fatigue in science centres}

From the first survey, top ten factors of museum fatigue in science centres were selected and used to illustrate when and how students likely feel fatigue in science centres. Also, through statistical analyses including T-test and ANOVA analysis, the features of students' museum fatigue in science centres were analysed and compared regarding student gender, school level, interest in science, grade of school science, the number of visits, and type of visits. The results that were found to be statistically significant are reported and discussed here.

\subsection{Main factors of museum fatigue in science centres}

Table 3 shows in sequential order the context, category and the number (and the ratio) of students who mentioned each of the top ten factors causing museum fatigue in science centres from the first survey. Nearly half (48.4\%) of the students said that "pain in the legs from walking and waiting in lines for a long time', a factor belonging to the Choice category in the Personal context, was the source of museum fatigue in science centres, suggesting that this factor must be considered as the most important. Also, many students seemed to feel museum fatigue in science centres was caused by the factors that belong to the 'Personal' context. Miles and Tout (1992) claimed that people feel 'museum fatigue' as a result of excessive information provided to them by the museum. A similar conclusion can be drawn here. $17.4 \%$ of students responded that they felt the information was hard to understand because there were too many things that they did not understand.

Factors of the Physical context and Socio-cultural context also seemed to be important in museum fatigue in science centres. Falk and Dierking (1992) claimed that even for a physically strong person, museums with hard floors, long corridors and few chairs could cause fatigue. However, it did not correspond to the results of Bitgood (2009), who concluded that the tendency of people to avoid unpleasant situations makes physical or mental museum fatigue of visitors highly unlikely. As shown in Table 3, the fact that two factors out of the ten main factors are of a Physical context shows that the Physical context has some impact on museum fatigue in science centres. However, regarding the number of responses it can be confirmed that the personal context is more dominant than any other contexts in science centres.

In addition, regarding the Prior knowledge category, many students felt museum fatigue in science centres, and the degree of feeling is also significant. On the other hand, regarding the Motivation and 
expectation category, the number of students who felt museum fatigue in science centres is small, and the degree of feeling is also small. These show that the fatigue caused by the difficulty in understanding the exhibits is higher than the fatigue posed by the lack of interest in science or science centres.

\section{Table 3. Ten main factors of museum fatigue in science centres}

\subsection{Average values of museum fatigue in science centres at Context and Category Levels}

Fig 2 shows that average value of museum fatigue in science centres of the Sociocultural context is the highest and that of the Personal context is the lowest at context levels. This result forms a contrast to the results of analysis regarding the number of responses. That is, most students feel museum fatigue in science centres, but the degree of the fatigue is not so high. Average values of museum fatigue in science centres of the Prior knowledge, Interaction with a visitor, Exhibition form, and Convenient facility categories are high at category levels. However, that of the Motivation and expectations and Control categories are low at category levels.

Fig 2. Average values of museum fatigue in science centres at Context and Category Levels

\subsection{Differences of museum fatigue in science centres at Context Level}

Table 4 shows a summary of the statistically significant differences of museum fatigue in science centres at the level of context according to student variables (i.e. gender, the level of schooling, the level of interest, the level of the grade in science, the number of visits to science centres and type to visits to science centres).

Table 4. Significant differences of museum fatigue in science centres according to the variables at the level of context

\subsubsection{Gender and museum fatigue in science centres}

T-tests were conducted for the comparison between male and female students. Respondents included 398 male students and 205 female students, a total of 603. From the analysis, it was found that there was no statistically significant gender difference in all contexts and categories.

This is one of the more interesting results from the analysis of museum fatigue, as it was not dependent on the gender of the student across all 12 categories of museum fatigue students feel in science centres, which was somewhat unexpected. It is particularly interesting that in many situations people's fatigue is known to be gender-dependent. For example, shopping fatigue was found to be significantly higher for men than women (Kruger \& Byker, 2009). On the other hand, it is a worldwide phenomenon that boys have a higher level of interest in science than girls (OECD, 2004; OECD, 2007; Mullis, Martin, \& Foy, 
2012). Gardner's comment that gender is the most significant variable related towards students' attitude to science is one which most science researchers and educators accept, as the meaning in the same (Schibeci, 1984; Becker, 1989; Weinburgh, 1995; Osborne, Simon \& Collins, 2003). Therefore, this result is contrary to the common understanding that male students have a more positive attitude towards school science than female students. Similarly, recent research on mathematics exhibitions in a science centre has shown that there is no gender difference in learning outcomes or interests (Vainikainen, Salmi \& Thurneberg, 2015). These opposite results could imply that the attitude towards science is different in schools to what it is in science centres.

\subsubsection{School levels and museum fatigue in science centres}

In the Personal context, middle school students tended to feel more fatigue than primary or high school students except for the Control category. For the Control category, primary school students seemed to feel more fatigue than middle and high school students. Among the Physical context factors, for the Orientation to the exhibits, Exhibition amount and Convenient facility categories, middle and high school students tended to feel more museum fatigue in science centres than primary school students. In the Socio-cultural context, for the Interaction with visitors' category, middle and primary school students seemed to feel more museum fatigue in science centres than high school students.

According to the school level comparison, middle school students tended to feel more museum fatigue in science centres than students of other levels of school. In particular, the level of exhibits was found to be either too high or too low for middle school students, causing them to feel museum fatigue in science centres. Therefore, if middle school students were able to learn about the exhibits before their visit to museums by doing prior research or being provided with worksheets before the visit (Rennie \& Mcclafferty, 1996), museum fatigue in science centres in the Prior knowledge category could be decreased. The contribution of prior knowledge to 'interest' varied depending on the different texts (Ainley, Hidi \& Berndorff, 2002). Therefore, designing science centres with a proper consideration of the different school levels, different texts and exhibit placement are necessary for more efficient learning in science centres. In the Control category, the primary school students felt more museum fatigue in science centres than high and middle school students. It might be because they could not control their observation in science centres. In the Prior knowledge category and the Interaction with visitors' category, high school students were analysed to have the lowest museum fatigue in science centres. It might be the case that high school students do not have a tendency to pay attention to visitors, and thus feel less museum fatigue in science centres because to some extent they are mature enough to enjoy the free view of the exhibits. On the other hand, middle and primary school students need to be able to visit science centres during the week when there are less visitors, and therefore the disturbance caused by group visitors can be reduced. Among the Physical context factors, for the Orientation to the exhibits, Exhibition amount, and Convenient facility categories, middle and high school students tended to feel more museum fatigue in 
science centres than primary school students. In this context, the lack of exhibits' information, information written in an unreasonable text size, and the lack of convenient facilities were identified as the sources of museum fatigue in science centres. For students in higher levels of school, more improvements could be made by putting reasonable size explanatory texts for each exhibit and by decreasing the elements that cause passive viewing, such as fixed exhibits. These seem to be some of the proper ways to improve learning resources and to lower museum fatigue in science centres. In the Sociocultural context, for the Interaction with visitors' category, middle and primary school students seemed to feel more museum fatigue in science centres due to their chitchat with other students, the noisy environment, and the disturbance caused by their taking pictures.

\subsubsection{Interest and level of grade in science and museum fatigue in science centres}

Concerning the relationship between the interest in science and museum fatigue in science centres, the latter was low in many categories (i.e., Prior knowledge, Motivation and expectation, Interests and beliefs, Control category, Choice category, Exhibition amount, Interaction with docents) for the group with a higher level of interest. This finding is in parallel with Hong \& Song's (2013) study showing that learning experience in science centres depends on prior knowledge and interest and that exhibits without new information have a negative effect on affective learning. This could, therefore, ensure that interest in science has a consistent influence on science learning regarding museum fatigue in science centres.

It was also found that students with high self-reported grades in school science tended to feel less museum fatigue in science centres in the Prior knowledge category and Motivation and expectation category of the Personal context, and the Exhibition amount category of the Physical context.

\subsubsection{Number of visits to science centres and museum fatigue in science centres}

As the number of visits to science centres increased, museum fatigue in science centres in the Prior knowledge and Motivation and expectation categories of the Personal context decreased. However, in the Interaction with visitors' category of the Socio-cultural context, museum fatigue in science centres increased with the number of visits. The relationship between the number of visits to museums and museum fatigue in science centres showed an inversely proportional relationship in the Prior knowledge and Motivation and expectation categories, but a proportional relationship in the Interaction with visitors' category. Students who had a low interest in science or science centres or students who did not want to go to science centres (both factors which belong to the Motivation and expectation category) showed lower fatigue as the number of visits increased. Still, it cannot be said for certain that museum fatigue was low in the Prior knowledge and Motivation and expectation categories because of the high number of visits due to responses from students who were interested in the science centres already, or whether it truly decreases with the number of visits. As Lumley (1988) showed, it is thought that students who answered that they 'had low fatigue in [the] Prior knowledge and Motivation and expectation categories and visited 
science centres often,' were already interested in science or science centres. It can be reconfirmed that museum fatigue in science centres, learning effects and students' interest in science or science centres are all very closely related to each other. Ryan \& Deci (2000) insisted that the feelings of competence, autonomy, relatedness, and self-determination be the basis for one's continued motivation. Consequently, it is important to encourage the students to have more interest in the exhibits before their visit to science centres. Additionally, in the Interaction with visitors' category, which included factors such as bumping into each other, chatting too much and lack of exhibition viewing time, museum fatigue increased as students visited science centres more.

\subsubsection{Type of visits to science centres and museum fatigue in science centres}

The results of this analysis showed that students who visited science centres alone felt the least museum fatigue in science centres in the Prior knowledge category even if the frequency of visit alone is lower than any other types of visit (alone: $2.2 \%$, with friends: $10.2 \%$, with family: $42.7 \%$, and as a school: 44.9\%). Solitary visitors are likely to read comments of exhibits (McManus, 1987). From this and our results, it can be argued that visiting museums alone can improve the effect of science learning in science centres regarding the Prior knowledge category. On the other hand, for the Motivation and expectation category of the Personal context and the Convenient facility category of the Physical context, students who visited science centres with their family were found to feel less museum fatigue in science centres than students who visited on a school visit. It might be the case that visiting museums with the family can help students to feel less museum fatigue in science centres and thus increase the effectiveness of science learning in science centres regarding motivation and expectation for visiting science centres.

\section{Discussion and Conclusions}

In this study, museum fatigue in science centres was investigated through two surveys. The purpose was to understand how students engage emotionally with science centres and how this engagement influences their science learning. The first survey consisted of open-ended questions and the second survey of Likert-type items. Based on the data from the first survey, 50 factors were identified as reported causes of museum fatigue in science centres by students. Through the factor analysis of the data from the second survey, the 50 factors were grouped into 12 categories (i.e., prior knowledge; motivation and expectations; interests and beliefs; control; choice; orientation to exhibits; exhibition form; exhibition amount; exhibition hall environment; convenient facility; interaction with visitors; and interaction with docents). These findings formed the basis of a framework of the factors causing museum fatigue in science centres which consists of three contexts, 12 categories and 50 factors. The most interesting result regarding the classification of factors is that "There are not enough exhibits" was placed in the Personal context - Prior knowledge category, while "There are too many exhibits" was put into the Physical context - Exhibition 
amount category. The factor "There are not enough exhibits" can be interpreted as not just a shortage of exhibits in the science centres but insufficient exhibits appropriate to the visitors' needs. The result implies that it is crucial to adjust the exhibit level to visitors' needs.

The features of museum fatigue in science centres were analysed with the data from the secondary survey. Appendix 3 shows the summary of main findings which appeared to be significant from the second survey; that is, the results of the comparisons of museum fatigue in science centres scores according to the six variables of the students. The findings about the features are summarised as follows. First, museum fatigue caused by understanding the exhibits is greater than that caused by the lack of interest in science or science centres. Second, the average value of museum fatigue of the Sociocultural context is the highest at context levels, but that of the Personal context is the lowest. Third, the average values of museum fatigue in science centres within the Prior knowledge, Interaction with a visitor, Exhibition form, and Convenient facility categories are high at category levels. However, that in the Motivation and expectations and Control categories are low at category levels. Fourth, museum fatigue was not dependent on the gender of all categories. Fifth, middle school students tended to feel more museum fatigue than students of other levels of school in general. Primary school students felt more museum fatigue than students of other levels of school in the Control category. High school students felt more museum fatigue than primary school students in the Orientation to the exhibits category. Sixth, museum fatigue was low in many categories for the group with a higher level of interest and with high selfreported grades in school science. In addition, as the number of visit to science centres increases, museum fatigue in the Prior knowledge and Motivation and expectation categories decreased, but museum fatigue in the Interaction with visitors' category increased. Finally, students who visited alone felt the least museum fatigue in the Prior knowledge category. On the other hand, students who visited with their family felt less museum fatigue than those who visited on a school visit in the Motivation and expectation category and the Convenient facility category.

On the basis of findings, we found six conclusions. First, the scientific knowledge of the students themselves about the exhibits are more critical than the attitude toward science, the design of the centre or the exhibits, and any other physical condition of persons and science centres. In the research, museum fatigue in the Prior knowledge category is the most significant, both quantitively and qualitatively, at category level. In addition, it is noticible that museum fatigue caused by understanding the exhibits is higher than that caused by the lack of interest in science or science centres. In previous research, the environment of science centres, the methods of exhibiting the exhibits, and affirmative attitudes toward science are more important topics for promoting the effectiveness of science education in science centres. However, this research shows that the promotion of students' prior knowledge about the exhibits is the most critical way to enhance the effectiveness of science learning in science centres.

Second, it seems that museum designers and science educators in science centres have to realise the importance of interaction between visitors in science centres. In this study, students felt museum fatigue 
more in the Sociocultural context than in any other context in terms of average value of museum fatigue in science centres at context level. In particular, museum fatigue in the Interaction with visitors category is estimated as a critical factor in terms of both the average value of museum fatigue and number of responses. However, according to study done by Barry (1998) \& Bitgood (2009) that included discussions among visitors about the exhibits, the Socio-cultural context can also decrease fatigue; this lets us know that an in-depth study of the socio-cultural context of museum fatigue is needed for further research.

Third, the findings of the research imply that attitudes towards science in both formal and informal science education should be differentiated. As our study found no gender differences in the students visiting the science centres in terms of museum fatigue, unlike previous studies showing a gender difference regarding attitudes toward science in school science education, it would seem that attitudes towards science are different in schools and science centres. It may, therefore, be appropriate to analyse that this difference came from the way of science education between formal and informal science education. Thus, it seems reasonable to argue that gender difference in school science could be alleviated by making up for the way of science education in science centres. A further point needs to be made with regard to the way of mutual cooperation.

Fourth, the fatigue caused by the inadequate level of exhibits demands modification of exhibits at each school level. That is, it is necessary to look at how to display exhibits according to visitors' knowledge and understanding because most of the science centres' exhibits are exhibited not by level of exhibits but by subjects or themes. Also, since the lack of guidance about the exhibits or the inadequacy of the information about exhibits were identified as causes of fatigue, measures to adjust the level of the exhibits should be considered.

Fifth, ways to both increase the number of visitors and distribute visitors throughout science centres should be considered. As this research showed, as the number of visits increased, museum fatigue in the Prior knowledge and Motivation and expectation categories decreased, but museum fatigue in the Interaction with visitors' category increased.

Finally, visitors need to find different types of visit that fit the purpose of their visit. McManus (1987) and Robinson (1928) argued that when people visit museums alone, they could concentrate more on the exhibits. In this study, within the same relationship analysis, results showed that people felt less fatigue only in terms of the prior knowledge categories when they visit museums alone. On the other hand, for other categories such as 'motivation and expectation' and 'convenient facility' ones, students who visited museums with their family had less museum fatigue in science centres than solo visitors. NRC (2009) found that parental participation and explanation enhanced the quality of students' engagement with exhibits. They also highlighted that the parents' conversations with their children depended on what they believed were the impacts of the exhibits on their children's learning. It seems that science centre visitors and teachers need to understand the difference between visiting alone, visiting as a school group and visiting as a family. 
Despite these findings, there remain some basic limitations inherent in this approach. It was impossible to identify all the factors about museum fatigue in science centres even though we collected the data from 603 students (11 18 years old) in an open-ended way. We relied on self-report data using Likert scale questionnaires when collecting the data. Such an approach could force students' responses and often unintentionally provide the participants with the expected response. Additionally, the data was dependent upon the memory of the participants who had visited science centres for three years to investigate comprehensive individual experience about science centres not in a specific centre. Therefore, it seemed that the data was disconnected from any specific science centre and self-reported recollections are often different from experiences at the moment. The other limitation involves the generalisation of results and the implication of the paper. This study was carried out with students in a single country which limits the generalizability of the findings. This limitation may have the most substantial effect on the sociocultural context since this context differs the most from culture to culture. Nevertheless, this research has led to a framework of factors causing museum fatigue in science centres. As these findings are based on empirical evidence, namely students' experience, they may aid science educators, museum designers and museum administrators in enhancing the learning effect in science centres. 


\section{References}

Ainley, M., Hidi, S. \& Berndorff, D. (2002). Interest, learning, and the psychological processes that mediate their relationship. Journal of Educational Psychology, 94(3), 545-561.

Barry, A. (1998). On interactivity: consumers, citizens and culture. In Macdonald, S. (1998). The Politics of Display: Museums, Science, Culture (pp. 98-117). Routledge.

Becker, B. J. (1989). Gender and science achievement: a reanalysis of studies from two meta-analyses. Journal of Research in Science Teaching, 26, 141-169.

Bitgood, S. (2009). Museum fatigue: a critical review. Visitor Studies, 12(2), 93-111.

Bitgood, S. (2009). When is "museum fatigue" not fatigue? Curator: The Museum Journal, 52(2), 193202.

Bitgood, S. \& Patterson, D. (1987). Principle of exhibit design. Visitor Behavior, 2(1), 4-6.

Child, D. (1990). The essential of factor analysis (2nd edition). London: Cassell Education Ltd.

Cota-McKinley, A. (1999). An empirical investigation of workload on the visitor experience: effects of exhibit size and time constraints on performance. (Doctoral dissertation). Ft. Collins, CO: Colorado State University.

Csikszentmihalyi, M. \& Hermanson, K. (1999). Intrinsic motivation in museums: why does one want to learn? In Hooper-Greenhill, E. (1999). The Educational Role of the Museum (2nd ed., pp. 146-160). Routledge.

Davey, G. (2005). What is museum fatigue? Visitor Studies Today, 8(3).

Dierking, L. \& Falk, J. (1994). Family behavior and learning in informal science settings: A review of research. Science Education, 78(1), 57-72. doi: 10.1002/sce.3730780104

Falk, J. H. (2001). Free-choice science learning: framing the discussion. In Falk, J. H. (2001). Free-Choice Science Education: How We Learn Science Outside of School (pp. 3-20). Teachers College Press.

Falk, J. H. \& Dierking, L. D. (1992). The museum experience. Washington, D.C.: Whalesback Books.

Falk, J. H. \& Dierking, L. D. (2000). Learning from museums: visitor experiences and the making of meaning. Altamira Press.

Falk, J. H. \& Dierking, L. D. (2002). Lessons without limit: how free-choice learning is transforming education. Altamira Press.

Falk, J. H., Koran, J. J. Jr., Dierking, L. D. \& Dreblow, L. (1985). Predicting visitor behavior. Curator: The Museum Journal, 28(4), 249-258. doi:10.1111/j.2151-6952

Friedman, A. J. (2010). The evolution of the science museum. Physics Today, 63(10), 45-51. https://doi.org/10.1063/1.3502548Gilman, B. (1916). Museum fatigue. The Scientific Monthly, 2(1), 62-74. Hein, G. E. (1998). Learning in the museum. Routledge.

Hofstein, A., \& Rosenfeld, S. (1996). Bridging the gap between formal and informal science learning. Studies in Science Education, 28, 87-112. 
Hong, O. \& Song, J. (2013). A new method of understanding learning in science centers: context diagrams of learning experiences. Visitor Studies, 16(2), 181-200.

Kruger, D. \& Byker, D. (2009). Evolved foraging psychology underlies sex differences in shopping experiences and behaviors. Journal of Social, Evolutionary, and Cultural Psychology, 3(4), 315-327.

Lamb, R. L., Annetta. L., Meldrum. J. \& Vallett. D. (2011). Measuring science interest: Rasch validation of the science interest survey. International Journal of Science and Mathematics Education, 10(3), 643668.

Lumley, R. (1988). The museum time-machine. Routledge.

Marcellini, D. \& Jensen, T. (1988). Visitor behavior in the National Zoo's Reptile House. Zoo Biology, 7, $329-338$.

McManus, P. M. (1987). It's the company you keep...: the social determination of learning-related behaviour in a science museum. International Journal of Museum Management and Curatorship, 6(3), 263-270.

McManus, P. M. (1992). Topics in museums and science education. Studies in Science Education, 20, 157-182.

Melton, A. (1935). Problems of installation in museums of art. New Series No. 14. Washington, DC: American Association of Museums.

Miles, R. \& Tout, A. (1992) Exhibitions and the public understanding of science. In Durant, J. (1992). Museums and the public understanding of science (pp. 27-33). Science Museum in association with the Committee on the Public Understanding of Science.

Mullis, I. V. S., Martin, M. O. \& Foy, P. (2012). TIMSS 2011 International Mathematics Report. MA: Boston College.

NRC (2009). Learning science in informal environments. Washington, D.C.: National Research Council.

OECD (2004). Learning for tomorrow's world: first results from PISA 2003. Paris: OECD.

OECD (2007). PISA 2006 science competencies for tomorrow's world. Volume I: Analysis. Paris: OECD.

Osborne, J., Simon, S. \& Collins, S. (2003). Attitudes towards science: A review of the literature and its implications. Attitude Towards Science, 25(9), 1049-1079.

Pompes, S. M., Walker, C. E. \& Spark, R. T. (2008). Knowledge and wonder: engagement with light and color in the hands-on optics project. In Yeger, R. E., \& Falk, J. H. (2008). Exemplary Science in Informal Education Settings. NSTA Press.

Rennie, L. J. (2007). Learning science outside of school. In Abell, S. K., \& Lederman, N. G. (2007). Handbook of Research on Science Education (pp. 125-167). Mahwah, NJ: Lawrence Erlbaum Associates.

Rennie, L. J. \& McClafferty, T. P. (1996). Science centres and science learning. Studies in Science Education, 27, 53-98.

Rennie, L. J., \& Williams, G. F. (2002). Science centers and scientific literacy: Promoting a relationship 
with science. Science education 86.5, 706-726.

Renninger, K. A. N. N. \& Hidi, S. (2011). Revisiting the conceptualization, measurement, and generation of interest. Educational Psychologist, 46(3), 168-184.

Robinson, E. (1928). The behavior of the museum visitor. American Association of Museums, New Series (5).

Ryan, R. M. \& Deci, E. L. (2000). Intrinsic and extrinsic motivations: classic definitions and new directions. Contemporary Educational Psychology, 25, 54-67.

Schibeci, R. A. (1984). Attitudes to science: an update. Studies in Science Education, 11, $26-59$.

Schiefele, U. (1998). Individual interest and learning, what we know and what we don't know. In L. Hoffman, A. Krapp, K. Renninger \& J. Baumert (Eds.), Interest and learning: Proceedings of the Seeon Conference on Interest and Gender (pp. 91-104). Kiel, Germany: IPN.

Soren, B. J. (1999). Meeting the needs of museum visitors. In Lord, G. D., \& Lord, B. (1999). The Manual of Museum Planning (2nd ed., pp. 55-67). The Stationary Office.

Vainikainena, M. P., Salmi, H. \& Thuneberg, H. (2015). Situational interest and learning in a science center mathematics exhibition. Journal of Research in STEM Education, 1(1), 15-29.

Weinburgh, M. (1995). Gender differences in student attitudes toward science: a meta-analysis of the literature from 1970 to 1991. Journal of Research in Science Teaching, 32, 387-398. 